\title{
Nanocomposites Based on Technical Polymers and Sterically Functionalized Soft Magnetic Magnetite Nanoparticles: Synthesis, Processing, and Characterization
}

\author{
S. Kirchberg, ${ }^{1}$ M. Rudolph, ${ }^{2}$ G. Ziegmann, ${ }^{1}$ and U. A. Peuker ${ }^{2}$ \\ ${ }^{1}$ Institute of Polymer Materials and Plastics Engineering, Clausthal University of Technology, 38678 Clausthal-Zellerfeld, Germany \\ ${ }^{2}$ Institute of Mechanical Process Engineering and Minerals Processing, TU Bergakademie Freiberg, 09599 Freiberg, Germany
}

Correspondence should be addressed to S. Kirchberg, stefan.kirchberg@tu-clausthal.de

Received 19 January 2012; Accepted 6 March 2012

Academic Editor: Sevan P. Davtyan

Copyright () 2012 S. Kirchberg et al. This is an open access article distributed under the Creative Commons Attribution License, which permits unrestricted use, distribution, and reproduction in any medium, provided the original work is properly cited.

This experimental study deals with the synthesis, processing, and characterization of highly filled nanocomposites based on polyvinyl butyral/magnetite $\left(\mathrm{PVB} / \mathrm{Fe}_{3} \mathrm{O}_{4}\right)$ and polymethylmethacrylate/magnetite $\left(\mathrm{PMMA} / \mathrm{Fe}_{3} \mathrm{O}_{4}\right)$. The nanoparticles are synthesized in an aqueous coprecipitation reaction and show a single particle diameter of approximately $15 \mathrm{~nm}$. The particles are sterically functionalized and covered by PVB and PMMA in a spray drying process. The synthesized compound particles are further processed by injection molding to test specimens with filler contents up to 14.5 vol.- $\%$. PVB and PMMA specimen are processed as a reference as well. The distribution of the nanoparticles is characterized by microscopy. Besides a minor number of agglomerates and aggregates the nanoparticles are distributed homogeneously in the PVB composites. Furthermore, the injection molded specimens are characterized with regard to their thermal degradation, polymer structure, and their mechanical and magnetic properties. The presence of nanoparticles capped with ricinoleic acid shows significant decrease in degradation temperature and in glass transition temperature of PVB. The degradation temperature of PMMA is increased by adding nanoparticles capped with oleic acid. Dynamic-mechanical properties as well as the magnetic permeability of PVB and PMMA are improved significantly by adding nanoparticles.

\section{Introduction}

Soft magnetic materials based on iron oxides are often used for electromagnetic screening devices, in electrical machines, for magnetic shielding, and in magnetorheological areas [1$3]$. The restrictions of the application of these materials are the relatively high hysteresis losses that can be reduced by using soft magnetic particles in a thermoplastic matrix [4].

The incorporation of nanosized particulate matter within a polymer matrix to create nanocomposites is a well-known technique to enhance or advance material properties. This fact has been employed for decades starting with the wellknown material Bakelite used in tires for cars around 1900 [5]. Nevertheless, the homogenous distribution and deagglomeration of the nanoparticles is still a current research topic. In the last twenty years there have been numerous studies on novel nanoparticle systems and a growing understanding in the synthesis, functionalization, and handling of nanoparticles. Unique "nano-" properties like super paramagnetic behavior for magnetite nanoparticles or extreme tensile strength for nanotubes have been described [6-9].

Nowadays, a growing interest lies in the engineering and processing of polymeric nanocomposites to create both highquality and affordable materials incorporating nanoparticles [10]. The goal is to produce composites with a high dispersity - the uniform distribution of primary nanoparticles within the polymer matrix-preserving the unique properties of the primary particles [11]. Polymer composites filled with nanoscaled particles can be produced either by bottomup [12-15] or top-down [16, 17] processes. In the bottom-up process the nanoparticles will be integrated in the polymer matrix by synthesis or solution process. Amongst a variety of others one method to incorporate especially a high amount 
of nanoparticles in a soluble polymer is the solution method, which has been introduced by Banert and Peuker [18]. These highly filled composites exceed a filling ratio of the particles phase of $30 \mathrm{wt} . \mathrm{\%}$.

Nanoparticles show a high affinity to agglomerate or aggregate. Therefore, a process has to be found to separate the particles from each other. In order to reach high filler contents in a nanocomposite with several components (nanoparticle, e.g., Magnetite, surfactant, e.g., fatty acids and polymer, e.g., PVB and PMMA) one has to investigate the theoretical limitations from the packing of spheres, which are 68 vol.- $\%$ and 74 vol.- $\%$ for body-centered cubic and face-centered cubic particle packing, respectively. In case of microparticle-filled composites, a maximum packing density up to $70 \mathrm{vol} .-\%$ can be processed by extrusion, kneading, and (micro) injection moulding processes [19, 20]. The challenge in using nanoparticle-filled composites is the very large specific surface of the fatty acid capped primary particles, which has to be surrounded by the polymeric matrix. However, the filler content of body-centred cubic and face-centred cubic particle packing cannot be reached in nanocomposites up to now.

Despite previous experiments with PMMA polymer matrices, PVB was found to stabilize the dispersion considerably caused by stronger interactions with the fatty acid coated magnetite particles $[21,22]$. The excellent adhesive and filmforming properties of PVB makes it applicable as safety glass interlayers, paints, lacquers, vanishes, printing inks, temporary binder, and adhesives. The injection molding and thermal as well as magnetic analysis of $\mathrm{PVB} / \mathrm{Fe}_{3} \mathrm{O}_{4}$ nanocomposites has not been reported in the literature up to now.

\section{Materials and Methods}

The precipitation reaction and the phase transfer (PT) are carried out in conventional laboratory glass ware. Iron salts $\left(\mathrm{FeSO}_{4} * 7 \mathrm{H}_{2} \mathrm{O}, \mathrm{FeCl}_{3} * 6 \mathrm{H}_{2} \mathrm{O}\right)$ purchased from Roth (Karlsruhe, Germany) and 26\% ammonium hydroxide purchased from Sigma-Aldrich Chemie GmbH (Munich, Germany) are used.

The solvent is dichloromethane (DCM) in technical quality since it is the aim to scale up the process. Both ricinoleic ( $\mathrm{RA}$ ) and oleic (OA) fatty acids are in technical quality as well and purchased from Sigma-Aldrich Chemie GmbH (Munich, Germany). Polyvinyl butyral (Mowital B $30 \mathrm{~T}$, Kuraray Europe GmbH, Frankfurt, Germany) and polymethylmethacrylate (Diakon CLG902, Lucite International, Rozenburg, The Netherlands) are used as matrix polymer. The solved polymer exists in coils of about $5 \mathrm{~nm}$ in diameter as measured by dynamic light scattering (DLS). Spray drying is accomplished by a laboratory cocurrent spray dryer (Büchi B-290, Büchi Labortechnik GmbH, Essen, Germany) with solvent recovery. The organosol is atomized with an external mixing two fluid nozzles with nitrogen as atomizing gas. A low drying temperature of $60^{\circ} \mathrm{C}$ is applied. In a cyclone the polymer-nanoparticle composite microparticles are separated from the gas stream with a median size of about $5 \mu \mathrm{m}$ as measured with laser diffraction.

The spray dried composite particles are characterized using a scanning electron microscope (Phenom, FEI, Eindhoven, The Netherlands) with a back scatter electron detector. For further processing purposes an injection molding machine (Arburg Allrounder 220S 150-60, Lossburg, Germany) is used to produce various test specimens $(35 \times 10 \times$ 4) $\mathrm{mm}^{3}$ for characterization. The distribution and agglomeration of the nanoparticles in the injection molded composite samples are characterized using a microscope (Zeiss Axiolab A1, Carl Zeiss MicroImaging GmbH, Jena, Germany) and a scanning electron microscope (Helios NanoLab 600, FEI, Eindhoven, The Netherlands) with inverted back scatter electron detector. Thermogravimetric analysis (TGA) is performed using a thermogravimetric analyzer (TGA Q5000 IR, TA Instruments, Alzenau, Germany) starting at $25^{\circ} \mathrm{C}$ up to $600^{\circ} \mathrm{C}$ in high-resolution mode (HiRes 5) with modulated heating rate from $10^{\circ} \mathrm{C} / \mathrm{min}$ to $0.2^{\circ} \mathrm{C} / \mathrm{min}$ under nitrogen atmosphere with respect to [23]. The balance measurement resolution accuracy is $0.1 \%$. For temperature calibration the well-known Curie temperature of a nickel standard sample has been measured as a reference.

Dynamic scanning calorimetry (DSC Q2000, TA Instruments, Alzenau, Germany) is done in temperature range between $0^{\circ} \mathrm{C}$ and $150^{\circ} \mathrm{C}$ with a heating rate of $10^{\circ} \mathrm{C} / \mathrm{min}$ under nitrogen atmosphere. For temperature calibration the melt temperature of indium, lead, tin, and zinc standards has been measured to achieve a minimum temperature deviation of $0.2^{\circ} \mathrm{C}$.

For mechanical characterization a dynamic mechanical thermal analyzer (DMTA) (DMA Q800, TA Instruments, Alzenau, Germany) in forced vibration single cantilever mode is used. The temperature ranges from $-30^{\circ} \mathrm{C}$ to $150^{\circ} \mathrm{C}$ at a heating rate of $3^{\circ} \mathrm{C} / \mathrm{min}$ and an induced frequency of $8 \mathrm{~Hz}$. An amplitude of $5 \mu \mathrm{m}$ (equal to a maximum strain of $\varepsilon \sim 1.4 \times 10^{-4}$ ) is applied for standard experiment. The temperature has been calibrated using indium, lead, tin, and zinc standards to achieve a minimum temperature deviation of $0.2^{\circ} \mathrm{C}$. The resolution of the loss factor $(\tan \delta)$ is $1 \times 10^{-4}$ which is the ratio of the loss modulus to the storage modulus. The repeating accuracy of storage modulus is $3 \%$.

The magnetic measurements are performed with a computer controlled hysteresis measurement system (Hysterograph, IMVT, TU Clausthal, Clausthal-Zellerfeld, Germany) similar to the one described in $[24,25]$. For all materials, permeability measurements versus magnetic field strength are carried out at ambient temperature and a frequency of $1 \mathrm{~Hz}$ in the region of magnetic field from 200 to $50000 \mathrm{~A} / \mathrm{m}$ with 50 measurement points. Furthermore, the low field permeability (at 3\% of maximum polarization induction) and the maximum permeability versus filler fraction are analyzed. Due to the low reachable polarization of a composite, which is linearly dependent on the filler fraction and the saturation polarization of the magnetic filler, the dependency of coercivity on filler fraction is measured at $0.07 \mathrm{~T}$ for the purpose of comparability. 


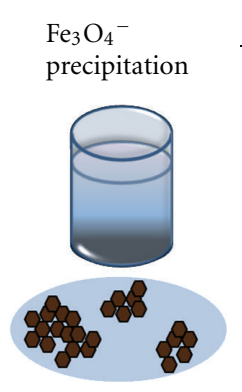

$X_{\text {Crystallite }} \approx 15 \mathrm{~nm}$

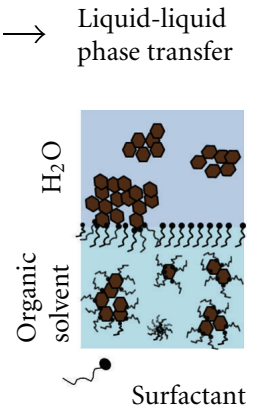

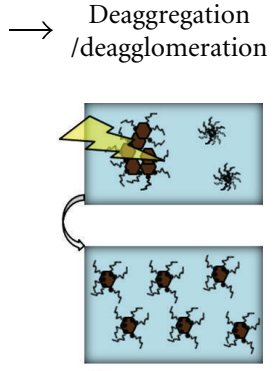

\& Energy

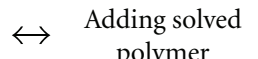

polymer

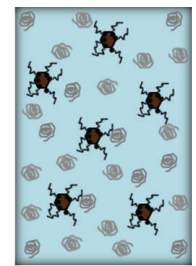

(26) Polymer coil

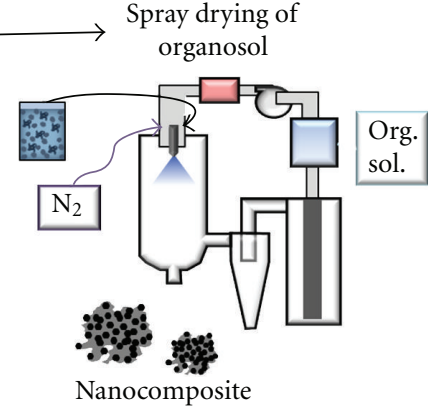

FIGURE 1: Scheme of the process chain for the synthesis of highly filled polymer-nanoparticle composites and the solution/spray drying process.

\section{Experimental}

In order to synthesize highly filled polymeric nanocomposites, the concept of a modular built process chain is investigated, as shown in Figure 1.

The first step can already be the nanoparticle synthesis for example in a well-understood precipitation reaction. In a further project a continuous precipitation reactor is being developed to allow for higher throughput [26]. The transfer of the synthesized nanoparticles in aqueous suspensions into an organic solvent is achieved in a unit process called liquidliquid phase transfer [8]. The aggregates and agglomerates are partially physical-chemically dispersed and the particle surface hydrophobized by fatty acid adsorption at the liquidliquid interface. Furthermore, still existing aggregates and agglomerates can be mechanically dispersed in a media mill or in the shear gradient of ultrasonic cavitation or rotorstator devices. The colloidal stability is achieved entropically by steric hindrance of the grafted fatty acid molecule layers. After or before the latter step the solved unbranched polymer is added. The polymer forms coils that are in the size order of the nanoparticles, depending on the solvent (good or bad) and the chain length [22]. Depending on whether the polymers adsorb on the nanoparticles surface the colloidal stability is the bottleneck of the chain of synthesis. In a previous study it was shown that PMMA as a nonadsorbing polymer leads to depletion flocculation whereas PVB will adsorb on the particles and furthermore stabilize the system [22]. The complex organosol with high dispersity-ideally homogeneous distribution of sterically stabilized primary nanoparticles-is then spray dried to "freeze" the high dispersed state and form a nanoparticle-polymer composite powder. In an agglomeration step, the fine powder from the spray dryer is processed to improve bulk flow by highpressure tabletizing and granulation.

The synthesized polymeric nanocomposites are further processed by injection molding to produce test specimen for material characterization. The processing parameters are shown in Table 1 for PVB and PMMA as well as their nanocomposites. The injection molded test specimens are microscopically, thermoanalytically, and magnetically characterized.
TABLE 1: Injection molding parameter.

\begin{tabular}{lcc}
\hline Parameter & PVB & PMMA \\
\hline Melt temperature $\left[{ }^{\circ} \mathrm{C}\right]$ & 150 & 250 \\
Flow rate $\left[\mathrm{cm}^{3} / \mathrm{s}\right]$ & 22 & 22 \\
Injection pressure $[\mathrm{bar}]$ & 800 & 800 \\
Packing pressure $[\mathrm{bar}]$ & 500 & 500 \\
Mold temperature $\left[{ }^{\circ} \mathrm{C}\right]$ & 80 & 80 \\
\hline
\end{tabular}

\section{Results and Discussion}

Figure 2 shows the synthesized and spray dried $\mathrm{PVB} / \mathrm{Fe}_{3} \mathrm{O}_{4}$ and $\mathrm{PMMA} / \mathrm{Fe}_{3} \mathrm{O}_{4}$ composite particles. The $\mathrm{PVB} / \mathrm{Fe}_{3} \mathrm{O}_{4}$ composite particles in Figure 2(a) are characterized by a wide particle size distribution and wrinkled surfaces. The particle shape of the PMMA/ $/ \mathrm{Fe}_{3} \mathrm{O}_{4}$ composite particles in Figure 2(b) appears more spherical, and the particles sizes are slightly smaller. However, the width of the particle size distribution is similar, which is due to the droplet formation with the nozzle.

Following injection molding the composites show different agglomeration of the nanoparticles at constant filler content, described by the black areas in Figure 3. The $\mathrm{PVB} / \mathrm{Fe}_{3} \mathrm{O}_{4}$ nanocomposite in Figures 3(a) and 3(b) shows uniform distributed nanoparticles with minor number of agglomerates compared to the $\mathrm{PMMA} / \mathrm{Fe}_{3} \mathrm{O}_{4}$ nanocomposite in Figures 3(c) and 3(d), which is characterized by a large number of agglomerated particles. The appearance of such agglomerate structures is due to the polymer nanoparticle interactions in the dispersion before spray drying $[22,27]$. Because of the beneficial attractive interactions between the fatty acid coated magnetite nanoparticles and PVB colloidal stability is improved.

Thermogravimetric analysis (TGA) is carried out starting from room temperature up to $600^{\circ} \mathrm{C}$ with modulated heating rate (HiRes 5) to determine the degradation behavior of PVB, PMMA, and their nanocomposites as well as to establish the filler content of $\mathrm{Fe}_{3} \mathrm{O}_{4}$ nanoparticles in the composites. The results are shown in Figure 4.

TGA results of PVB and its nanocomposites in Figure 4(a) show a weight loss of about $2 \mathrm{wt} .-\%$ at around $100^{\circ} \mathrm{C}$ induced by the melting of PVB and vaporization 


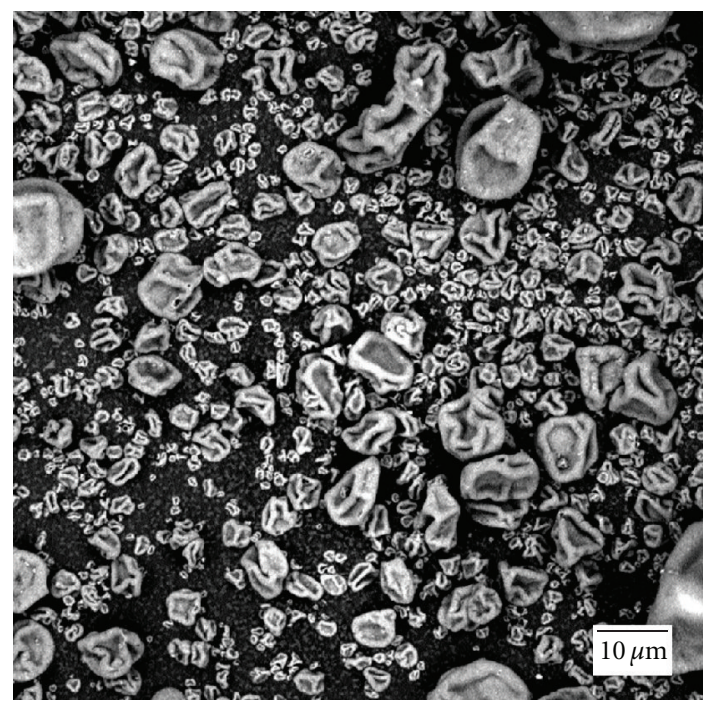

(a)

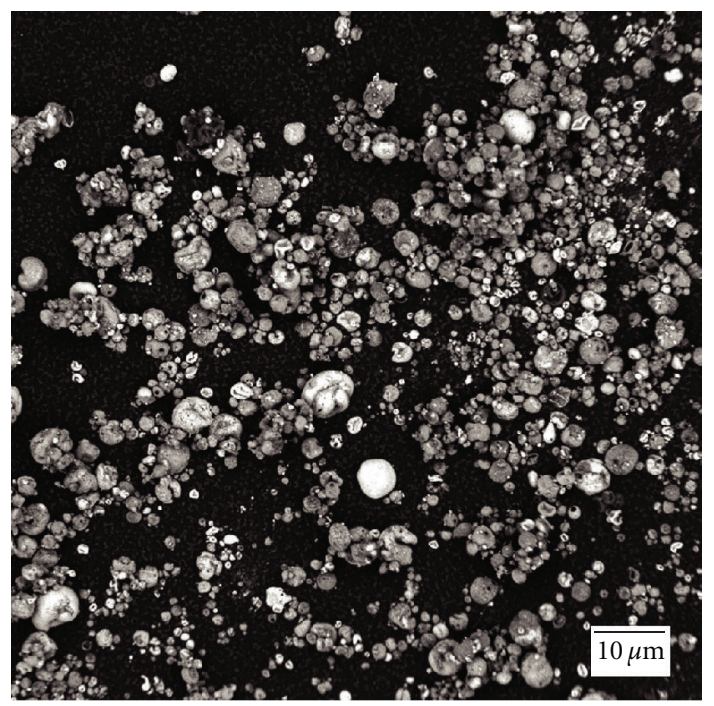

(b)

FIGURe 2: Synthesized and spray dried (a) $\mathrm{PVB} / \mathrm{Fe}_{3} \mathrm{O}_{4}$ and (b) $\mathrm{PMMA} / \mathrm{Fe}_{3} \mathrm{O}_{4}$ composite particles (back scattering SEM, magnification 2.000x).

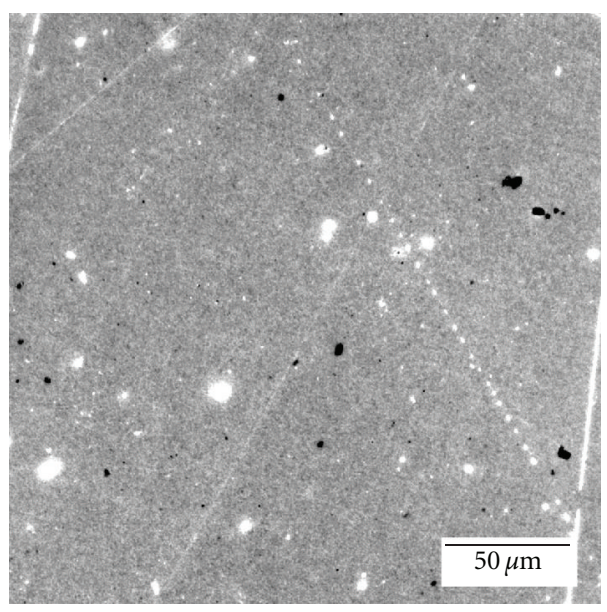

(a)

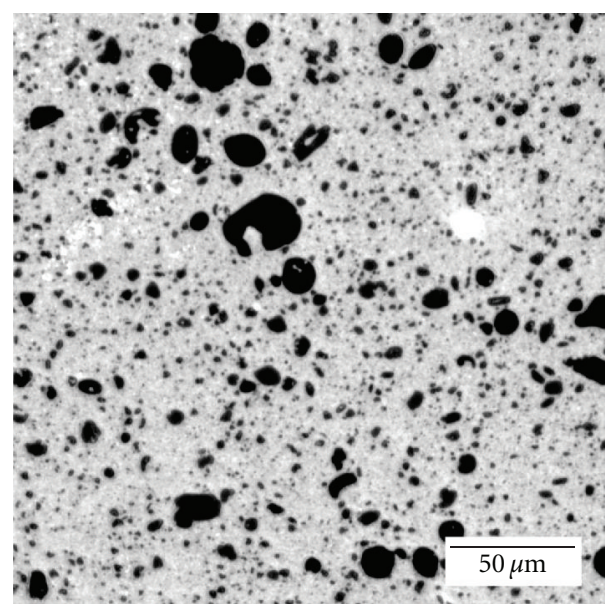

(c)

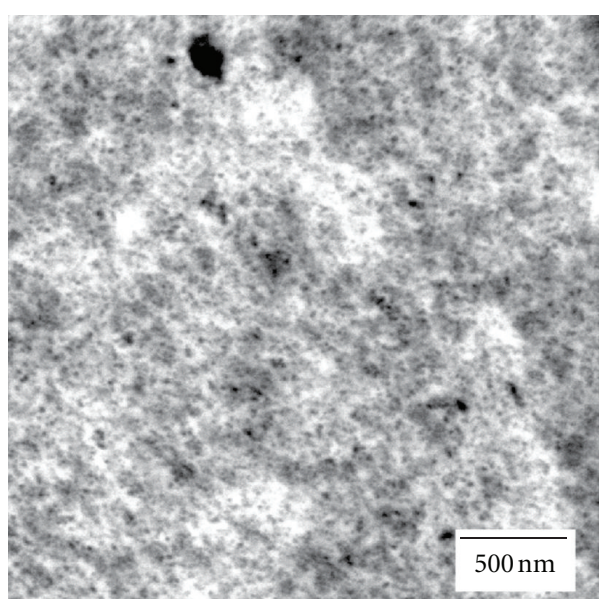

(b)

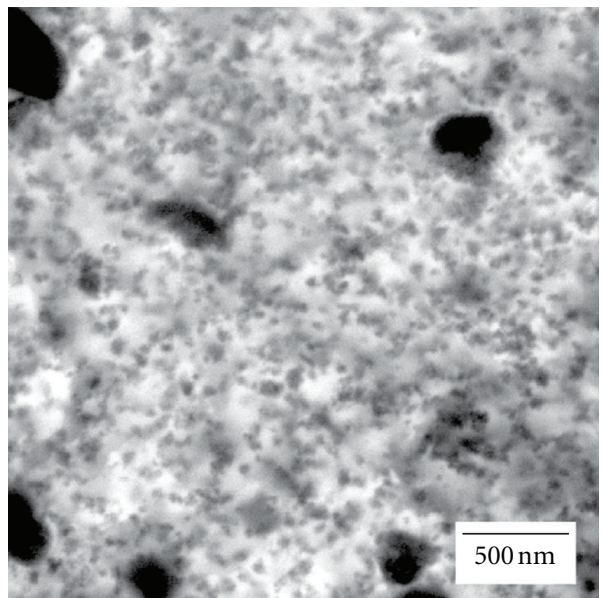

(d)

Figure 3: Injection molded ( $\mathrm{a}, \mathrm{b}) \mathrm{PVB} / \mathrm{Fe}_{3} \mathrm{O}_{4}$ and $(\mathrm{c}, \mathrm{d}) \mathrm{PMMA} / \mathrm{Fe}_{3} \mathrm{O}_{4}$ composite samples at comparable nanoparticle filler content ((a, c) inverted bright field optical microscopy, magnification 350x, (b, d): inverted back scattering SEM, magnification 35.000x). 


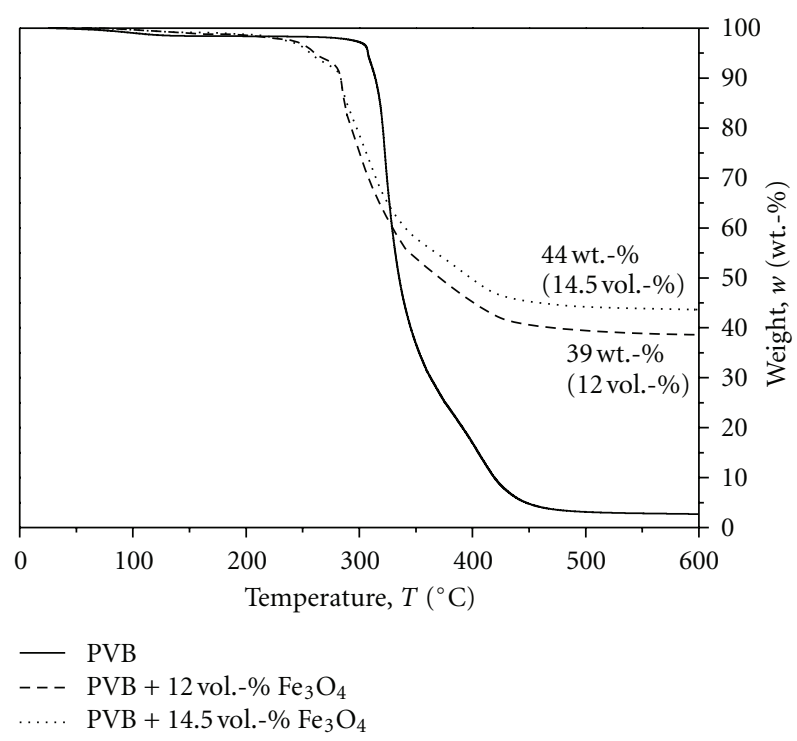

(a)

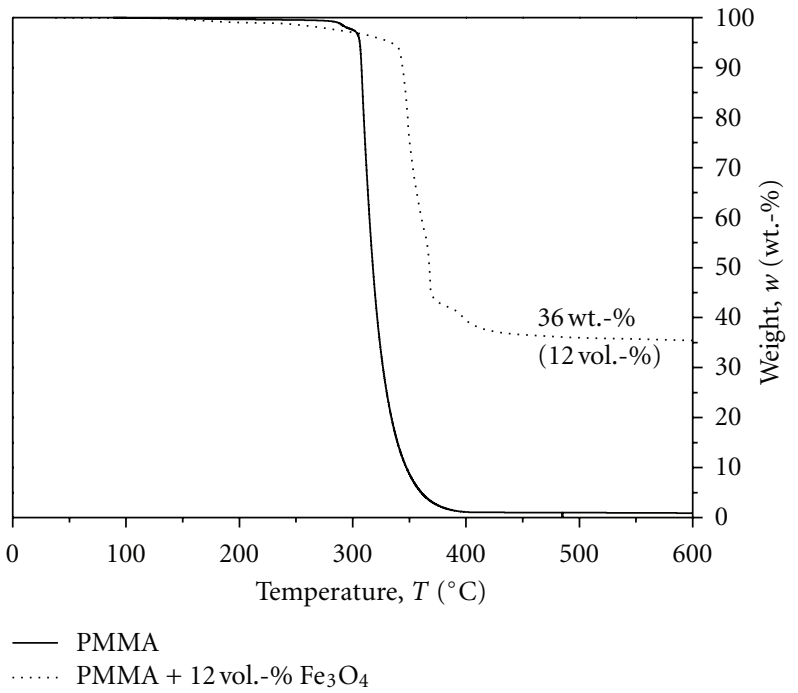

(b)

FIgure 4: Thermogravimetric analysis of (a) PVB and PVB/ $\mathrm{Fe}_{3} \mathrm{O}_{4}$ nanocomposites and (b) PMMA and PMMA/Fe $\mathrm{O}_{4}$ nanocomposites.

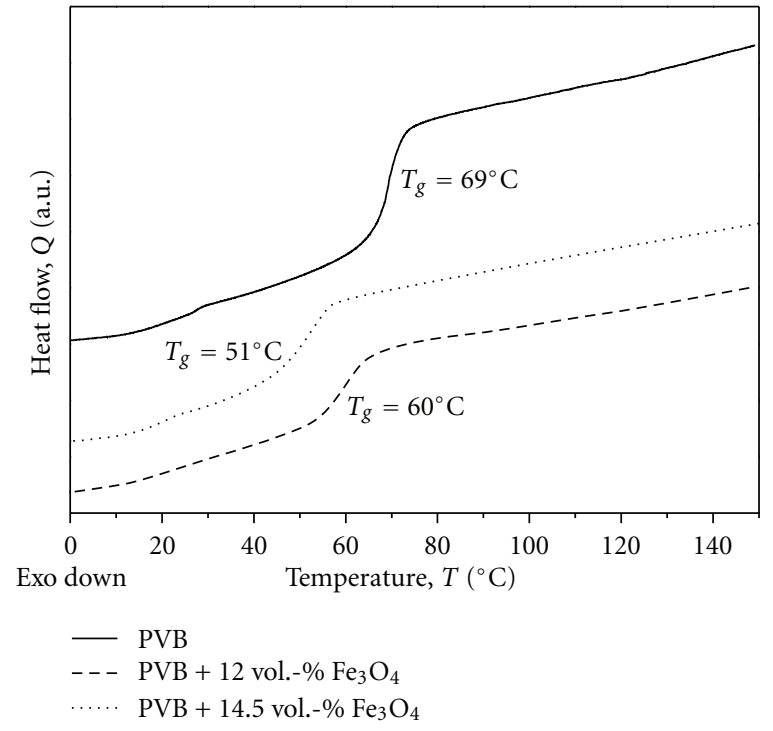

(a)

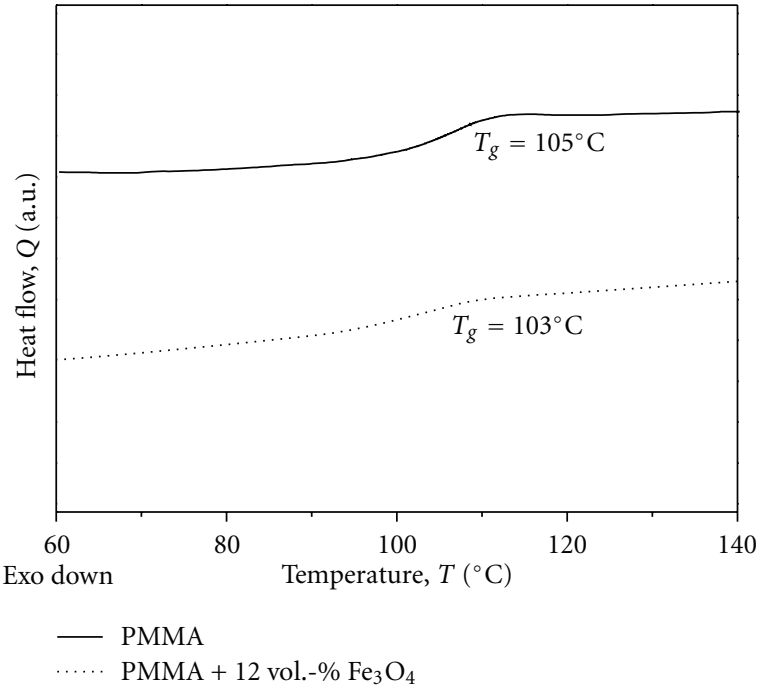

(b)

FIGURE 5: Dynamic scanning calorimetry of (a) PVB and PVB/ $/ \mathrm{Fe}_{3} \mathrm{O}_{4}$ nanocomposites and (b) PMMA and $\mathrm{PMMA} / \mathrm{Fe}_{3} \mathrm{O}_{4}$ nanocomposites.

of volatiles as components of the technical grade fatty acids. Thermal degradation of PVB nanocomposites starts at lower temperature $\left(230^{\circ} \mathrm{C}\right)$ compared to pure $\operatorname{PVB}\left(302^{\circ} \mathrm{C}\right)$. However, the opposite behavior is obtained for PMMA and $\mathrm{PMMA} / \mathrm{Fe}_{3} \mathrm{O}_{4}$ nanocomposites (Figure 4(b)). Hence, adding $\mathrm{Fe}_{3} \mathrm{O}_{4}$ nanoparticles reduces the thermal stability of PVB and increases thermal stability of PMMA. This can be explained by the increased amount of microsized agglomerates in PMMA nanocomposites, which reduces the mobility of polymer chains while heating, which has also been described for microparticle filled polymeric composites $[19,20]$. The well-distributed nanoparticles in the PVB nanocomposites surround the polymer chains homogeneously and may act as lubricants, which increases the mobility of the polymer chains and consequently reduces thermal stability of PVB. Regarding the filler content of $\mathrm{Fe}_{3} \mathrm{O}_{4}$ nanoparticles, the residual mass at $600^{\circ} \mathrm{C}$ is determined considering [26] 39 wt.$\%$ (equal to 12 vol.-\%) and 44 wt.-\% (equal to 14.5 vol.-\%), respectively. The residue of $\mathrm{PVB}$ at $600^{\circ} \mathrm{C}$ is about $3 \mathrm{wt} .-\%$.

Dynamic scanning calorimetry (DSC) is determined to explain the influence of nanoparticles on the glass transition temperature of PVB. DSC is done in temperature range between $0^{\circ} \mathrm{C}$ and $150^{\circ} \mathrm{C}$ using heating rate of $10^{\circ} \mathrm{C} / \mathrm{min}$ and nitrogen atmosphere. The results are shown in Figure 5. 


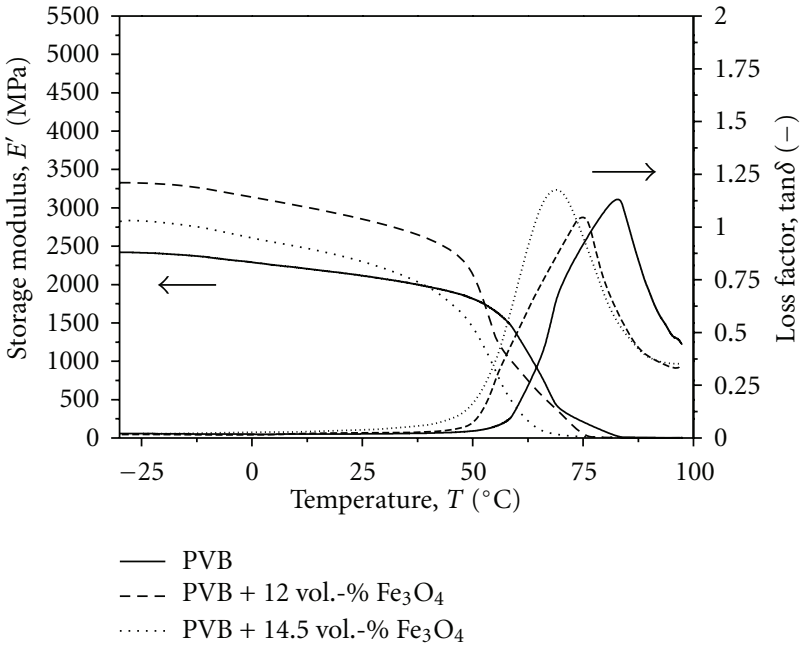

(a)

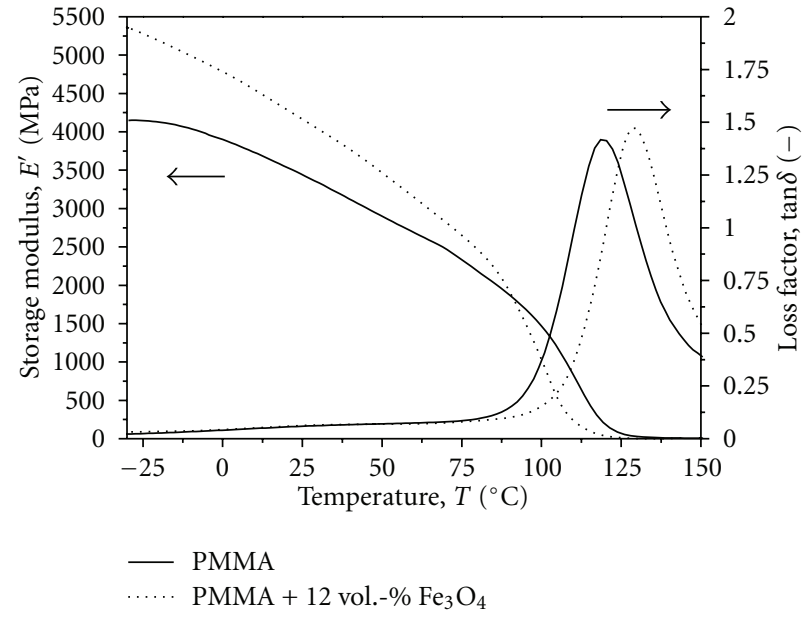

(b)

Figure 6: Dynamic mechanical analysis of (a) PVB and PVB/ $/ \mathrm{Fe}_{3} \mathrm{O}_{4}$ nanocomposites and (b) PMMA and PMMA/Fe $\mathrm{P}_{4}$ nanocomposites.

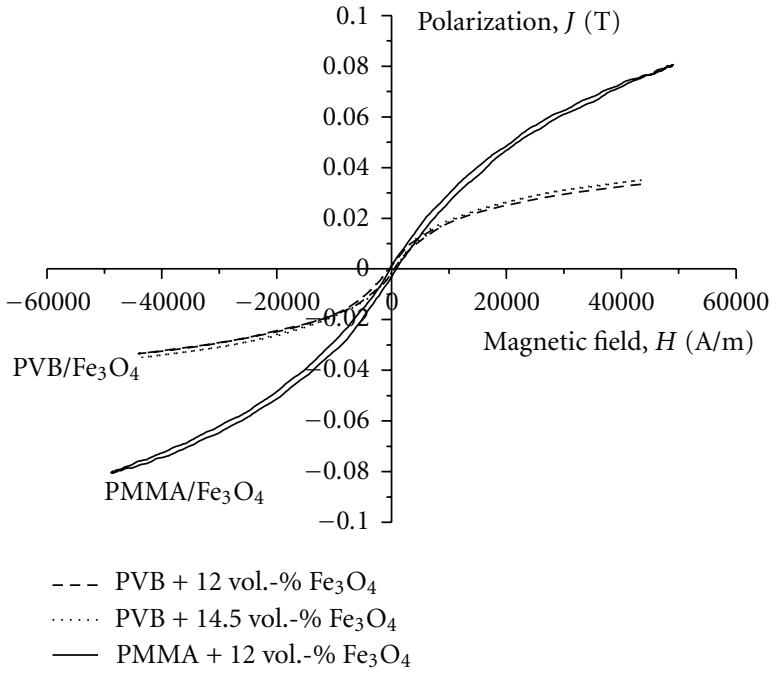

Figure 7: Magnetic hysteresis of $\mathrm{PMMA} / \mathrm{Fe}_{3} \mathrm{O}_{4}$ and $\mathrm{PVB} / \mathrm{Fe}_{3} \mathrm{O}_{4}$ nanocomposites.

Dynamic scanning calorimetry of PVB and PVB/ $/ \mathrm{Fe}_{3} \mathrm{O}_{4}$ nanocomposites in Figure 5(a) reveals a significant decrease of glass transition temperature $\left(\mathrm{T}_{\mathrm{g}}\right)$ with increasing nanoparticle filler content. The $\mathrm{T}_{\mathrm{g}}$ of PVB is reduced about $9^{\circ} \mathrm{C}$ and $18^{\circ} \mathrm{C}$ for $\mathrm{PVB}+12$ vol.- $\% \mathrm{Fe}_{3} \mathrm{O}_{4}$ and $\mathrm{PVB}+14.5$ vol.- $\%$ $\mathrm{Fe}_{3} \mathrm{O}_{4}$, respectively. Regarding the TGA results in Figure 4(a), increasing filler content of well-distributed $\mathrm{Fe}_{3} \mathrm{O}_{4}$ nanoparticles may increase the mobility of the polymer chains in PVB whereas the glass transition temperature will be reduced. In case of PMMA-based nanocomposites the glass transition temperature of PMMA is not significantly affected by adding $\mathrm{Fe}_{3} \mathrm{O}_{4}$ nanoparticles (see Figure 5(b)).

The mechanical behavior of PVB and PMMA as well as their nanocomposites is assessed using dynamic mechanical analysis (DMA) in a temperature range from $-30^{\circ} \mathrm{C}$ to
TABLe 2: Magnetic properties of $\mathrm{PMMA} / \mathrm{Fe}_{3} \mathrm{O}_{4}$ and $\mathrm{PVB} / \mathrm{Fe}_{3} \mathrm{O}_{4}$ nanocomposites.

\begin{tabular}{lcc}
\hline Property & $\begin{array}{c}\text { PMMA + 12 vol.-\% } \\
\mathrm{Fe}_{3} \mathrm{O}_{4}\end{array}$ & $\begin{array}{c}\mathrm{PVB}+12 \text { vol.-\% } \\
\mathrm{Fe}_{3} \mathrm{O}_{4}\end{array}$ \\
\hline Coercivity $[\mathrm{A} / \mathrm{m}]$ & 458 & 398 \\
Remanence $[\mathrm{T}]$ & 0.0016 & 0.001 \\
Saturation polarization $[\mathrm{T}]$ & 0.115 & 0.042 \\
Max. permeability [-] & 3.4 & 3 \\
Magnetic losses $\left[\mathrm{J} / \mathrm{m}^{3}\right]$ & 83 & 33 \\
\hline
\end{tabular}

$100^{\circ} \mathrm{C}$ and $150^{\circ} \mathrm{C}$, heating rate of $3^{\circ} \mathrm{C} / \mathrm{min}$, displacement amplitude of $5 \mu \mathrm{m}$, and frequency of $8 \mathrm{~Hz}$. Figure 6 shows the storage modulus $\mathrm{E}^{\prime}$ and loss factor $(\tan \delta)$ of the examined materials.

Figure 6 shows that the storage modulus $\mathrm{E}^{\prime}$ of $\mathrm{PVB}$ and PMMA is significantly increased by filler content. However, adding 14.5 vol.- $\%$ nanoparticle reduces storage modulus compared to PVB with 12 vol.- $\%$ nanoparticle. The nanoparticles cause failures in the polymer matrix. With increasing filler content the number of failures increases and the mechanical strength decreases. In general, storage modulus of PMMA and its nanocomposite shows significantly higher values than that of PVB and its nanocomposites in the examined temperature range caused by higher glass transition temperature of PMMA compared to PVB. In the temperature range of glass transition temperature of $\mathrm{PVB}$ and PMMA storage modulus strongly decreases by softening of the polymer material. Furthermore, the decrease in storage modulus induced by the glass transition of PVB takes place at lower temperatures with increasing filler content. The decrease in glass transition temperature correlates to the DSC results in Figure 5. The loss factor describes the damping behavior of the composites. The peak temperature of the loss 
factor of PVB is shifted to lower temperature with increasing filler content. In case of PMMA the opposite behavior is determined. Hence, adding nanoparticles to PVB reduces damping behavior, whereas an improvement of damping behavior was found by adding nanoparticles to PMMA.

Magnetic properties are investigated by magnetic hysteresis to show the influence of the incorporated soft magnetic $\mathrm{Fe}_{3} \mathrm{O}_{4}$ nanoparticles on the magnetic behavior of the nanocomposites. Results of magnetic characterization are illustrated in Figure 7 and listed in Table 2.

Magnetic hysteresis in Figure 7 shows lower saturation polarization of $\mathrm{PVB} / \mathrm{Fe}_{3} \mathrm{O}_{4}$ nanocomposites compared to $\mathrm{PMMA} / \mathrm{Fe}_{3} \mathrm{O}_{4}$ nanocomposites at constant filler content and equal magnetic field. Furthermore, the enclosed surface area of the hysteresis slopes characterizes the magnetic (hysteresis) losses of the nanocomposites. $\mathrm{PVB} / \mathrm{Fe}_{3} \mathrm{O}_{4}$ nanocomposites show significant lower surface area and consequently lower magnetic losses compared to $\mathrm{PMMA} / \mathrm{Fe}_{3} \mathrm{O}_{4}$ nanocomposites. Table 2 summarizes the magnetic properties of $\mathrm{PMMA} / \mathrm{Fe}_{3} \mathrm{O}_{4}$ and $\mathrm{PVB} / \mathrm{Fe}_{3} \mathrm{O}_{4}$ nanocomposites at constant filler content of 12 vol.- $\%$.

Magnetic properties of the examined nanocomposites in Table 2 show lower coercivity, saturation polarization, and magnetic losses of $\mathrm{PVB} / \mathrm{Fe}_{3} \mathrm{O}_{4}$ nanocomposites compared to $\mathrm{PMMA} / \mathrm{Fe}_{3} \mathrm{O}_{4}$ nanocomposites. Remanence and maximum permeability of the nanocomposites are comparable. According to Herzer [28], lower particle size of the well-distributed nanoparticles in $\mathrm{PVB} / \mathrm{Fe}_{3} \mathrm{O}_{4}$ nanocomposites induces lower coercivity compared to the agglomerated $\mathrm{PMMA} / \mathrm{Fe}_{3} \mathrm{O}_{4}$ nanocomposites.

\section{Conclusions}

$\mathrm{PVB} / \mathrm{Fe}_{3} \mathrm{O}_{4}$ and $\mathrm{PMMA} / \mathrm{Fe}_{3} \mathrm{O}_{4}$ nanocomposites with filler content up to 14.5 vol.- $\%$ were synthesized, spray dried, and further processed in injection molding process. The well-dispersed $\mathrm{Fe}_{3} \mathrm{O}_{4}$ nanoparticles show well-distributed nanoparticles in the injection molded $\mathrm{PVB} / \mathrm{Fe}_{3} \mathrm{O}_{4}$ nanocomposites. Thermal stability, glass transition temperature, and peak temperature of the loss factor of PVB will be reduced by adding nanoparticles. The opposite behavior was determined for PMMA/ $\mathrm{Fe}_{3} \mathrm{O}_{4}$ nanocomposites. Storage modulus of PVB and PMMA increases below glass transition temperature by adding $\mathrm{Fe}_{3} \mathrm{O}_{4}$ nanoparticles. The softening of PVB and PMMA nanocomposites starts at lower temperature compared to the unfilled polymer. Magnetic losses, coercivity and saturation polarization of $\mathrm{PVB} / \mathrm{Fe}_{3} \mathrm{O}_{4}$ nanocomposites were reduced compared to $\mathrm{PMMA} / \mathrm{Fe}_{3} \mathrm{O}_{4}$ nanocomposites caused by the uniform distribution of nanoparticles in PVB.

\section{Acknowledgment}

The authors would like to thank the Deutsche Forschungsgemeinschaft (DFG) for financial support (Project no. PE 1160/7-1; ZI 648/16-1).

\section{References}

[1] M. Sarasa, M. Bosse, D. Gerling, G. Ziegmann, and G. Kastinger, "Plastic moulded soft magnetic materials for electrical machines," in Proceedings of the Low Voltage Electrical Machines Conference, Brünn, Czech Republic, 2004.

[2] B. O. Park, K. H. Song, B. J. Park, and H. J. Choi, "Miniemulsion fabricated $\mathrm{Fe}_{3} \mathrm{O}_{4}$ /poly (methyl methacrylate) composite particles and their magnetorheological characteristics," Journal of Applied Physics, vol. 107, no. 9, Article ID 09A506, 2010.

[3] B. J. Park, F. F. Fang, and H. J. Choi, "Magnetorheology: materials and application," Soft Matter, vol. 6, no. 21, pp. 5246$5253,2010$.

[4] C. G. Goetzel, Treatise on Powder Metallurgy: Applied and Physical Powder Metallurgy, vol. 2, Interscience Publishers, New York, NY, USA, 1950.

[5] A. C. Balazs, T. Emrick, and T. P. Russell, "Nanoparticle polymer composites: where two small worlds meet," Science, vol. 314, no. 5802, pp. 1107-1110, 2006.

[6] A. S. Teja and P. Y. Koh, "Synthesis, properties, and applications of magnetic iron oxide nanoparticles," Progress in Crystal Growth and Characterization of Materials, vol. 55, no. 1-2, pp. 22-45, 2009.

[7] P. A. Dresco, V. S. Zaitsev, R. J. Gambino, and B. Chu, "Preparation and properties of magnetite and polymer magnetite nanoparticles," Langmuir, vol. 15, no. 6, pp. 1945-1951, 1999.

[8] S. Machunsky, P. Grimm, H. J. Schmid, and U. A. Peuker, "Liquid-liquid phase transfer of magnetite nanoparticles," Colloids and Surfaces A, vol. 348, no. 1-3, pp. 186-190, 2009.

[9] R. H. Baughman, A. A. Zakhidov, and W. A. De Heer, "Carbon nanotubes - the route toward applications," Science, vol. 297, no. 5582, pp. 787-792, 2002.

[10] J. H. Koo, Polymer Nanocomposites. Processing, Characterization, and Applications, McGraw-Hill Nanoscience and Technology Series, McGraw-Hill, New York, NY, USA, 2006.

[11] U. Wagenknecht, B. Kretzschmar, P. Pötschke et al., "Polymere Nanokomposite mit anorganischen Funktionsfüllstoffen," Chemie-Ingenieur-Technik, vol. 80, no. 11, pp. 1683-1699, 2008.

[12] P. M. Ajayan, L. S. Schadler, and P. V. Braun, Nanocomposite Science and Technology, Wiley-VCH, Weinheim, Germany, 2003.

[13] S. Breitung-Faes and A. Kwade, "Nano particle production in high-power-density mills," Chemical Engineering Research and Design, vol. 86, no. 4, pp. 390-394, 2008.

[14] G. Broza, M. Kwiatkowska, Z. Rosłaniec, and K. Schulte, "Processing and assessment of poly(butylene terephthalate) nanocomposites reinforced with oxidized single wall carbon nanotubes,” Polymer, vol. 46, no. 16, pp. 5860-5867, 2005.

[15] X. D. Zhou and H. C. Gu, "Synthesis of PMMA-ceramics nanocomposites by spray process," Journal of Materials Science Letters, vol. 21, no. 7, pp. 577-580, 2002.

[16] P. Pötschke, M. Abdel-Goad, I. Alig, S. Dudkin, and D. Lellinger, "Rheological and dielectrical characterization of melt mixed polycarbonate-multiwalled carbon nanotube composites," Polymer, vol. 45, no. 26, pp. 8863-8870, 2004.

[17] P. Pötschke, S. M. Dudkin, and I. Alig, "Dielectric spectroscopy on melt processed polycarbonate-multiwalled carbon nanotube composites," Polymer, vol. 44, no. 17, pp. 50235030, 2003.

[18] T. Banert and U. A. Peuker, "Preparation of highly filled superparamagnetic PMMA-magnetite nano composites using the solution method," Journal of Materials Science, vol. 41, no. 10, pp. 3051-3056, 2006. 
[19] S. Kirchberg and G. Ziegmann, "Thermogravimetry and dynamic mechanical analysis of iron silicon particle filled polypropylene," Journal of Composite Materials, vol. 43, no. 12, pp. 1323-1334, 2009.

[20] S. Kirchberg, Einfluss von Füllgrad und Geometrie weichmagnetischer Partikel auf das Verarbeitungs- und Materialverhalten ausgewählter Thermoplaste, Papierflieger, Clausthal-Zellerfeld, Germany, 2009.

[21] M. Rudolph, U. A. Peuker, S. Kirchberg, C. Turan, and G. Ziegmann, "Synthesis of highly filled nanomagnetite polymeric composites via sterically stabilized organosols and the spray drying process," Chemie Ingenieur Technik, vol. 8, no. 8, pp. 774-780, 2009.

[22] M. Rudolph and U. A. Peuker, "Coagulation and stabilization of sterically functionalized magnetite nanoparticles in an organic solvent with different technical polymers," Journal of Colloid and Interface Science, vol. 357, no. 2, pp. 292-299, 2011.

[23] M. Rudolph, J. Erler, and U. A. Peuker, "A TGA-FTIR perspective of fatty acid adsorbed on magnetite nanoparticlesdecomposition steps and magnetite reduction," Colloids and Surfaces A, vol. 397, pp. 16-23, 2012.

[24] M. Pott-Langemeyer, W. Riehemann, and W. Heye, "Magnetic properties of meltspun Fe-Si-Al ribbons," Anales de Fisica B, vol. 86, pp. 232-234, 1990.

[25] D. Ramin and W. Riehemann, "Automatic Measurement of the Magnetic Properties of Extreme Soft Magnetic Ferromagnetic Materials," Technisches Messen, vol. 68, no. 3, pp. 116-125, 2001.

[26] M. Heckele and W. K. Schomburg, "Review on micro molding of thermoplastic polymers," Journal of Micromechanics and Microengineering, vol. 14, no. 3, pp. R1-R14, 2004.

[27] M. Rudolph, C. Turan, S. Kirchberg, G. Ziegmann, and U. A. Peuker, "Nanoparticles in Organic Solvents With Polymers Stability and Consequences upon Material Synthesis Through Spray Drying and Melt Moulding," in Nanoformulation. Special Publications, G. Tiddy and R. B. H. Tan, Eds., Royal Society of Chemistry, Cambridge, UK, 2012.

[28] G. Herzer, "Nanocrystalline soft magnetic alloys," in Handbook of Magnetic Materials, vol. 10, pp. 417-462, North Holland, 1997. 

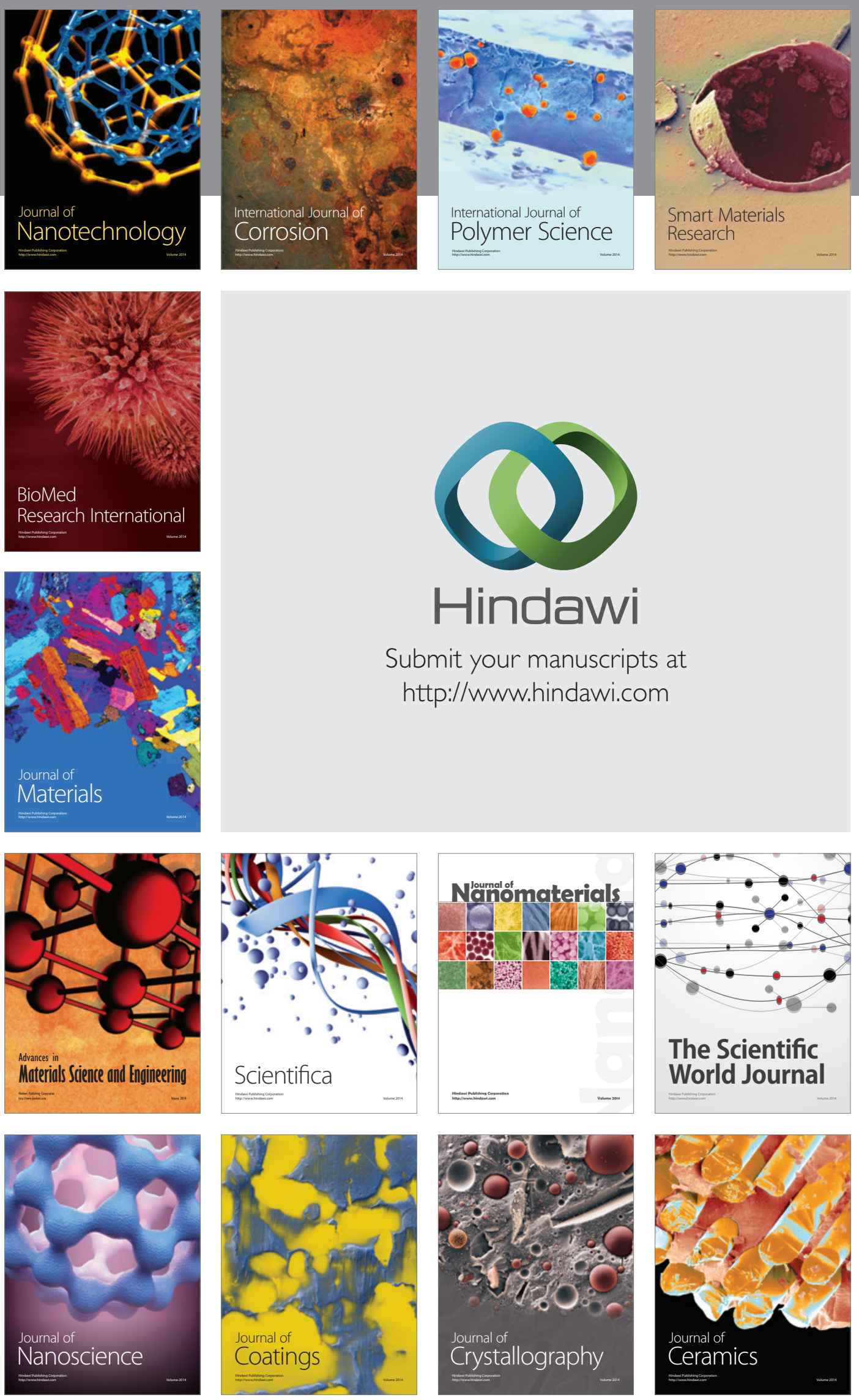

The Scientific World Journal

Submit your manuscripts at

http://www.hindawi.com

\section{World Journal}

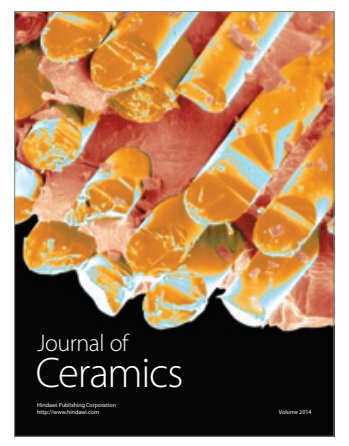

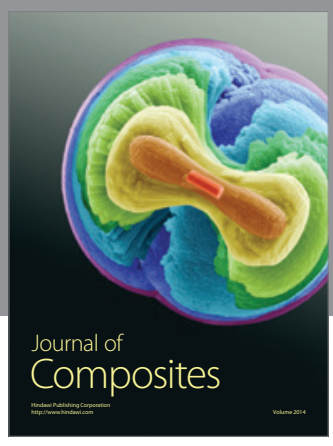
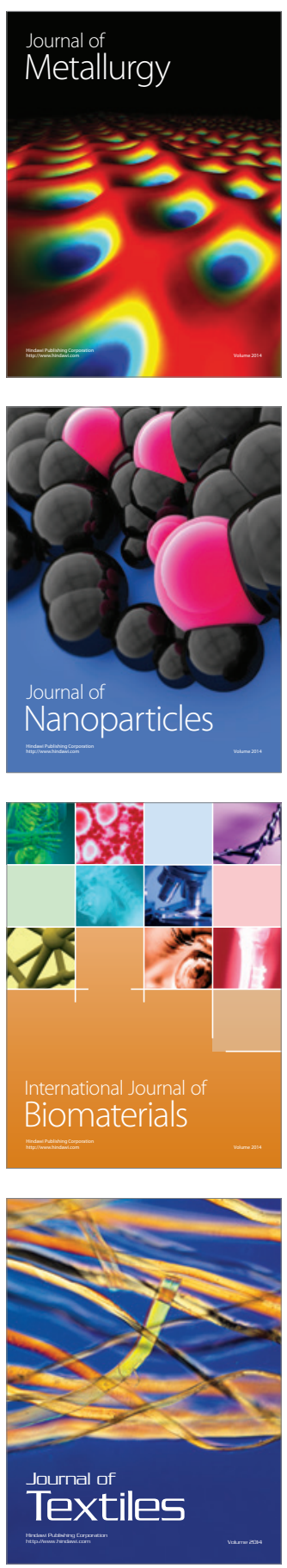